\title{
Padrões de Produtividade de Autores em Periódicos e Congressos na Área de Contabilidade no Brasil: um Estudo Bibliométrico
}

Patterns of Productivity of Brazilian Authors in Accounting Magazines and Congress: a Study Bibliometric

Geraldo Alemandro Leite Filho* Mestre em Controladoria e Contabilidade pela FEA/USP. Professor do Departamento de Ciências Contábeis da UNIMONTES, Montes Claros/MG, Brasil.

*Endereço: Rua Um, 55, Bairro Barcelona Parque, Montes Claros/MG, 39400-000. E-mail: geraldo.alemandro@unimontes.br 


\section{ResUmo}

O objetivo do estudo foi analisar a produtividade científica dos autores em anais de congressos e periódicos brasileiros na área de Contabilidade. No referencial teórico apresentaram-se estudos bibliométricos correlatos em outras áreas. O método utilizado foi a pesquisa descritiva, análise quantitativa de dados; universo e amostra foram os periódicos e congressos científicos brasileiros na área de Contabilidade. Os principais resultados evidenciaram uma padronização de publicação da área, a predominância de autores do sexo masculino, indícios de forte endogenia de instituições nacionais, existência de concentração de autoria vinculada a poucas instituições que apresentaram as mais altas freqüências relativas nos veículos de publicação.

Palavras-chave: Bibliometria; produtividade científica; pesquisa; Contabilidade.

\section{AbSTRACT}

The aim of the study was to analyze the author's scientific productivity in Accounting Brazilian proceedings and magazines. It was show bibliometrics studies in other areas. The method was the descriptive research, quantitative analysis of data, universe and sample were the Accounting Brazilian magazines and scientific Congress. The results evidenced a standardization of publication, a male predominance of authors, indications of strong emphasis of national institutions, existence of authorship concentration linked to few institutions that presented the highest relative frequencies in the publication vehicles studied.

Key words: Bibliometrics; scientific productivity; research; Accounting. 


\section{Aspectos Introdutórios}

A área de Contabilidade como ciência, no Brasil, tem-se expandido nos últimos anos, observando-se uma evolução contínua, em razão de várias mudanças econômicas e sociais, aumento expressivo do número de programas de pósgraduação e, conseqüentemente, o aumento da produção científica, do impacto econômico que ela produz nas organizações e na sociedade, bem como da evolução da Contabilidade em todo o mundo.

Do ponto de vista acadêmico, comparando-se a outras áreas, a discussão sobre a produção do conhecimento na área de Contabilidade é contemporânea e encontra estudos desta natureza a partir dos anos 80 e 90, fortalecendo-se sua discussão nos anos 2000. Validando esta assertiva, Theóphilo e Iudícibus (2005) verificaram uma mudança de paradigma na pesquisa contábil brasileira neste período, evidenciado pela preocupação em estudos com foco empírico e pela aproximação dos trabalhos a um formato científico, apesar da pouca diversidade das abordagens metodológicas.

Nesta mesma linha, podem-se citar os trabalhos de Riccio, Carastan e Sakata (1999), que investigaram a produção científica brasileira na área de Contabilidade de 1962 a 1999; Frezatti e Borba (2000) estudaram os padrões de revistas científicas internacionais na área de Contabilidade; Oliveira (2001) analisou o conteúdo e a forma dos periódicos científicos de Contabilidade no Brasil; Moriki e Martins (2003) estudaram o referencial bibliográfico de dissertações de dois programas de pós-graduação na área de Contabilidade; Leite (2004) pesquisou a relação orientador-orientando e sua associação com a produção de teses e dissertações nos programas de pós-graduação em Contabilidade; Santana (2004) investigou a produção científica em Contabilidade Social no período de 1990 a 2003; Cardoso, Mendonça, Riccio e Sakata (2005) estudaram as publicações científicas em Contabilidade de 1990 a 2003; Cardoso, Pereira e Guerreiro (2004) estudaram a produção científica em custos; Martins e Silva (2005) analisaram as referências bibliográficas de um Congresso da área de Contabilidade em 2003 e 2004; Silva, Oliveira e Ribeiro (2005) fizeram um estudo comparativo de períodos em um periódico da área de Contabilidade no Brasil.

Com o propósito de contribuir para a ampliação dessa discussão, a questão de pesquisa deste estudo indaga: Quais são os padrões de produtividade dos autores que publicaram trabalhos em anais de congressos e periódicos na área de Contabilidade no Brasil? A distribuição da autoria das publicações vem adequandose aos padrões propostos pela teoria bibliométrica? 
Assim, o objetivo principal deste trabalho é analisar, sob o ponto de vista da teoria bibliométrica, a produtividade científica dos autores em anais de congressos e periódicos na área de Contabilidade brasileira. Como objetivos específicos: a) comparar a produtividade na área de Contabilidade com as demais áreas do conhecimento, sob o ponto de vista de Lei de Lotka; b) identificar características de autores, veículos de publicação, instituições e localidades; c) comparar os veículos de publicação em Contabilidade; d) descrever autores mais produtivos na área.

Observou-se que estudos bibliométricos da produção científica de Contabilidade já ocorreram no Brasil, destacando-se os trabalhos de Riccio et al. (1999), Cardoso et al. (2005), Moriki e Martins (2003), Santana (2004), Martins e Silva (2005). Apesar da contribuição substancial dos referidos artigos, observa-se que eles não enfatizaram uma análise detalhada dos padrões de produtividade dos autores, veículos de publicação, instituições e localidades mais citados nos periódicos e anais de congressos específicos da área de Contabilidade.

Acredita-se que o tipo de análise, aqui proposta, pode trazer contribuições complementares aos estudos acima referenciados, levantar evidências, tendências, potencialidades, modismos e padrões, proporcionando a possibilidade de reflexão sobre quem publica na área de Contabilidade no Brasil, comparando a obra com a de outras áreas, e com os padrões internacionais, além da possibilidade de fomentar a discussão da construção do conhecimento da área.

\section{Referencial Teórico}

Argumenta-se que o papel fundamental da produção do conhecimento na área de Contabilidade, assim como em qualquer área do conhecimento, é o de servir de referência para praticantes e estudiosos. Nesse contexto, inserem-se os programas de pós-graduação, pois se acredita que é a partir deles que há a formação de pesquisadores, professores, mestres e doutores, que irão contribuir para esta produção de conhecimento. Outro aspecto diz respeito à própria origem dos referidos programas de pós-graduação, linhas de especialização, vocação e definição de linhas de pesquisa em cada um deles, bem como a temática dos principais periódicos e anais de congressos de Contabilidade no país. Compreendese que a renovação e o vigor da produção científica, no âmbito de cada programa de pós-graduação, ocorre essencialmente em função da própria produção científica e por aquilo que ela reflete na forma de publicação científica. Assim, a publicação presente nos periódicos e anais de congressos da área originária dessa produção constitui o caminho da pesquisa científica da área. 
Volpato (2002), ao discutir aspectos da publicação científica, nas diversas áreas do conhecimento, assevera que uma das principais responsabilidades do pesquisador é publicar os resultados das pesquisas em periódicos que são aceitos na comunidade científica, para que haja divulgação do conhecimento. Para tanto existem indexadores e indicadores bibliométricos que objetivam atestar a qualidade do periódico ao qual será submetido o artigo para possível publicação.

Nesse contexto, Campos (2003) observou que a avaliação da qualidade de um periódico, artigo científico, ou mesmo a produção científica de um determinado autor pode ser feita também pelos indicadores bibliométricos. Tais indicadores de desempenho são úteis para avaliar a pesquisa acadêmica, orientar rumos e estratégias de financiamento de pesquisas.

Vanti (2002) assevera que a bibliometria é um conjunto de métodos de pesquisa da área das Ciências da Informação que utiliza análise quantitativa de dados, para mapear a estrutura de um campo científico e também como ferramenta para análise do comportamento dos pesquisadores em suas decisões na construção deste conhecimento.

Vários são os estudos bibliométricos, nas diversas áreas do conhecimento, destacando-se em educação o trabalho de Alvarenga (2000), que avaliou a pesquisa na Revista Brasileira de Estudos Pedagógicos de 1944 a 1974, por meio de indicadores bibliométricos; em economia, Bino, Subash e Ramanathan (2002) avaliaram a concentração de autores em sete periódicos publicados na Índia entre 1990 e 2002; em administração, a coletânea de Bertero, Caldas e Wood (2005) trazem uma gama de trabalhos publicados na Revista de Administração de Empresas com análises bibliométricas nas diversas subáreas da administração brasileira; na área de ciências da Informação, Souza e Rasche (1999) estudaram a produção científica de informação documentária no Estado de Santa Catarina de 1973 a 1993; na área de antropologia, Urbizagastegui-Alvarado e Oliveira (2001) avaliaram a produtividade de antropólogos brasileiros, usando indicadores bibliométricos. Consta ainda em Urbizagastegui-Alvarado (2002) um estudo comparativo da lei bibliométrica de Lotka, em distintas áreas de conhecimento no Brasil.

Estudos bibliométricos específicos de Contabilidade são descritos em Zeff (1996), autor que pesquisou em revistas norte-americanas, na área de Contabilidade, padrões de autoria, cientificidade e a continuidade dos periódicos. Como principais resultados, indicou que a área demonstra forte endogenia e que há certa concentração em autores e instituições acadêmicas.

Willians e Rodgers (1996) pesquisaram os padrões de pesquisa, produtividade de autores e criação de novos conhecimentos no periódico norte-americano The 
Accounting Review [TAR], no período de 1967 a 1993. Os principais resultados indicaram que houve estratificação em publicações em outras áreas do conhecimento e que havia forte correlação com um agrupamento de universidades de elite, sendo que autores com maior produtividade no TAR estariam, de alguma forma, ligados a estas instituições. Observaram também que esta elite de autores, que estava produzindo artigos na área de Contabilidade, cresceu em outras áreas das ciências sociais, especialmente em economia e psicologia cognitiva.

Fogarty (2004) pesquisou a produção do conhecimento de Contabilidade de recém-formados doutores norte-americanos, egressos desde 1977. O estudo revelou indícios de que a manutenção da produtividade dos autores estava associada ao status institucional outorgado pela universidade. Além disso, a continuidade nas publicações poderia ser explicada por fatores institucionais e pessoais. Quanto aos fatores pessoais, autores que têm publicado mais em suas carreiras tendem a permanecer mais tempo nas atividades escolares, principalmente quando há incentivos, tais como participação em eventos, congressos e encontros de pesquisa. $\mathrm{O}$ autor assevera que isto pode ser interpretado como diferença motivacional.

Chung, Pak e Cox (1992) estudaram os padrões de pesquisa na literatura contábil norte-americana por meio de indicadores bibliométricos, além de verificar a regularidade existente nas publicações. Os resultados empíricos revelaram forte regularidade bibliométrica existente na literatura de Contabilidade, fornecendo indícios de aproximação da lei bibliométrica de Lotka. Contudo observaram certa concentração institucional, em que sete programas de pós-graduação eram responsáveis por mais de 33\% de toda a produção científica na área, indicando forte domínio institucional na produção científica contábil norte-americana.

Cardoso et al. (2005) avaliaram a distribuição, características metodológicas e a evolução temática das publicações e produção dos autores brasileiros de textos de Contabilidade, nas revistas de administração e economia de 1990 a 2003. Utilizaram indicadores bibliométricos para avaliar a produtividade dos autores no referido período. Os principais resultados revelaram que a participação de textos de Contabilidade nos referidos periódicos pode ser considerada baixa $(2,95 \%)$, concentração de pesquisa publicada em poucos autores com grande número de artigos publicados; comparandose com outros trabalhos internacionais e nacionais, os autores classificaram a produtividade dos autores brasileiros de Contabilidade como baixa, e que a produtividade destes autores difere dos padrões da lei bibliométrica de Lotka.

Leal, Oliveira e Soluri (2003) analisaram, sob o ponto de vista bibliométrico, 551 artigos na área de finanças, publicados entre 1974 e 2001 em periódicos nacionais de administração e economia. Os resultados demonstraram que a maioria dos 
artigos apresentou somente um autor, a produtividade dos autores nacionais está concentrada e difere dos padrões descritos pela lei bibliométrica de Lotka.

Moriki e Martins (2003) pesquisaram o referencial teórico de teses e dissertações de programas de pós-graduação em Contabilidade no ano 2000. Os resultados constataram considerável dispersão de fontes bibliográficas, que dificultou a detecção de um padrão de referências bibliográficas, e os autores demonstraram postura conservadora quanto às fontes consultadas, devido à concentração de livros e à baixa frequiência de artigos de periódicos nacionais, internacionais, anais de congressos e seminários.

Santana (2004) investigou a pesquisa de Contabilidade social no Brasil de 1990 a 2003, utilizando análise bibliométrica. Como resultados principais, o autor encontrou indícios de concentração de artigos nos últimos sete anos pesquisados (89\%) e na temática de Balanço Social (45\%). Observou ainda que a produção é pequena no que diz respeito a periódicos avaliados pelo Qualis Capes (11,8\% do total). Verificou ainda uma concentração de artigos em poucos autores, além de evidências de endogenia na área de Contabilidade Social.

Martins e Silva (2005) estudaram a plataforma teórica de artigos apresentados em um congresso na área de Contabilidade nos anos de 2003 e 2004. Os resultados evidenciaram uma variabilidade de obras de mesma natureza, destacando-se livros nacionais, produção conjugada a forte dispersão e distinção de fontes bibliográficas entre os trabalhos, o que não possibilitou a caracterização de um padrão de referências nos artigos da área. Observaram ainda que os autores foram conservadores, por enfatizarem livros e raramente consultarem periódicos, anais de congressos e sítios da internet.

\section{Abordagem Metodológica}

Este trabalho caracteriza-se como pesquisa empírico-analítica, cujo tipo de abordagem pode ser considerado descritivo, pois visa descrever as características de autores e publicações em periódicos e anais de congressos de Contabilidade no Brasil. Gil (1996, p. 46) assevera que "as pesquisas descritivas visam à descrição das características de determinada população ou fenômeno, e têm por objetivo levantar as opiniões, atitudes e crenças de uma população". A opção por uma pesquisa descritiva obedeceu aos critérios listados por Mattar (1996), já que o propósito era descrever as características dos autores, estimar a proporção de elementos numa população que compartilhasse determinados padrões, descobrir ou verificar a existência de relação entre variáveis. 
A definição do universo da pesquisa englobou todos os periódicos e congressos nacionais específicos de Contabilidade, classificados segundo o documento Qualis de periódicos científicos - triênio 2004-2006 da área de avaliação Administração/ Turismo, classificados com conceitos A, B ou C. Segundo o referido documento, os periódicos e congressos específicos de Contabilidade no Brasil são:

\section{Tabela 1: Definição do Universo da Pesquisa}

\begin{tabular}{|l|l|c|l|}
\hline ISSN & Título do periódico / congresso & Classificação & Circulação \\
\hline $1519-7077$ & Revista Contabilidade e Finanças & A & Nacional \\
\hline $1516-7011$ & UnB Contábil & C & Nacional \\
\hline $1516-215 X$ & Revista de Contabilidade do Mestrado da UERJ & B & Local \\
\hline & Encontro da Anpad (EnAnpad) & A & Nacional \\
\hline & Congresso USP de Controladoria e Contabilidade & A & Nacional \\
\hline
\end{tabular}

Inicialmente optou-se por coletar os dados de todos os periódicos e anais de congressos listados na Tabela 1. Contudo decidiu-se avaliar somente veículos de publicação que tivessem abrangência nacional, ficando a amostra da pesquisa restrita a dois periódicos e dois anais de congressos. O período de análise ficou determinado desde a criação do periódico/congresso até o ano de 2004, conforme especificado na tabela a seguir:

\section{Tabela 2: Amostra e Período Pesquisado}

\begin{tabular}{|l|c|c|}
\hline Veículos de publicação & Período analisado & Anos \\
\hline Revista Contabilidade e Finanças & 1989 a 2004 & 16 anos \\
\hline UnB Contábil & 1998 a 2004 & 7 anos \\
\hline EnAnpad (Área: CCG-Contabilidade e Controle Gerencial) & 1997 a 2004 & 8 anos \\
\hline Congresso USP de Controladoria e Contabilidade & 2001 a 2004 & 4 anos \\
\hline
\end{tabular}

O instrumento utilizado para coleta e análise dos artigos foi um roteiro estruturado em banco de dados em planilha MS Excel®, tendo como base o ano, veículo de publicação, vinculação acadêmica dos autores, Estado da federação, e características das referências bibliográficas. Após a estruturação do referido roteiro, fez-se um pré-teste em uma série de dez artigos e, posteriormente, foram introduzidas algumas mudanças, tais como vinculação acadêmica, sexo e número de autores. Feitas as correções, ele foi aplicado nos veículos de publicação supracitados.

$\mathrm{Na}$ contagem dos autores procurou-se seguir as recomendações de Urbizagastegui-Alvarado (2002, p. 15), utilizando-se a contagem completa de autores, "quando cada autor (principal e/ou secundário) é creditado com uma contribuição".

A análise de dados fora dividida em duas categorias: na primeira, foi feita uma análise descritiva por veículo de publicação do perfil dos autores, quantidade de 
artigos por autor, sexo, vínculo institucional, localidade e artigos por autor. $\mathrm{Na}$ segunda a análise focou-se a produtividade dos autores, seguindo-se modelos sugeridos pela lei bibliométrica de Lotka. Optou-se ainda por utilizar testes estatísticos para avaliar o ajustamento das observações empíricas com os padrões preconizados pela referida lei.

Como limitações da pesquisa, assume-se que a amostragem por ser intencional e não probabilística, invalida o caráter de inferência da pesquisa para outros periódicos e anais de congressos de Contabilidade no Brasil. Outra limitação refere-se à desconsideração das características metodológicas dos artigos e características das referências bibliográficas deles, que não foi o objetivo deste trabalho que focou apenas características de autoria. Contudo, os dados serviram para traçar padrões de produtividade dos autores nos referidos veículos de publicação analisados.

\section{Resultados e Discussão}

Conforme se observa na abordagem metodológica, foram analisados periódicos e anais de congressos na área de Contabilidade no Brasil. Primeiramente procedeu-se à análise descritiva do perfil dos autores dos artigos apresentados nos veículos de publicação, separando-os pelo número de autores, total de artigos e o índice de autores por artigo, conforme demonstrado na tabela a seguir.

\section{Tabela 3: Perfil dos Autores}

\begin{tabular}{|c|c|c|c|c|c|c|c|c|c|c|c|}
\hline \multirow{2}{*}{ Veículo / autor } & \multicolumn{2}{|c|}{ EnAnpad } & \multicolumn{2}{|c|}{ Revista USP } & \multicolumn{2}{|c|}{ UnB Contábil } & \multicolumn{2}{|c|}{ Congresso USP } & \multirow{2}{*}{ Média } & \multirow{2}{*}{ DesvPad } & \multirow{2}{*}{ CV } \\
\hline & Quant. & $\%$ & Quant. & $\%$ & Quant. & $\%$ & Quant. & $\%$ & & & \\
\hline 1 Autor & 51 & $21,3 \%$ & 104 & $50,5 \%$ & 48 & $60,8 \%$ & 96 & $25,4 \%$ & $39,5 \%$ & $19,2 \%$ & $48,5 \%$ \\
\hline 2 Autores & 122 & $51,0 \%$ & 64 & $31,1 \%$ & 18 & $22,8 \%$ & 131 & $34,7 \%$ & $34,9 \%$ & $11,9 \%$ & $34,0 \%$ \\
\hline 3 Autores & 48 & $20,1 \%$ & 12 & $5,8 \%$ & 9 & $11,4 \%$ & 86 & $22,8 \%$ & $15,0 \%$ & $7,8 \%$ & $52,0 \%$ \\
\hline Mais de 3 autores & 18 & $7,5 \%$ & 26 & $12,6 \%$ & 4 & $5,1 \%$ & 65 & $17,2 \%$ & $10,6 \%$ & $5,4 \%$ & $51,0 \%$ \\
\hline Total artigos & 239 & $100,0 \%$ & 206 & $100,0 \%$ & 79 & $100,0 \%$ & 378 & $100,0 \%$ & 226 & 123 & $54,5 \%$ \\
\hline Total autores & 448 & & 274 & & 118 & & 889 & & 432 & 333 & $77,0 \%$ \\
\hline Autores / Artigo & 1,87 & & 1,33 & & 1,49 & & 2,35 & & 1,76 & 0,45 & $25,8 \%$ \\
\hline
\end{tabular}

Quanto ao perfil dos autores, verificou-se que, na média, a maioria da produção veiculada na área $(39,5 \%)$ referiu-se a trabalhos de um autor. Esta categoria também apresentou a maior dispersão entre as demais, explicada pelo fato de que, nos anais de congressos, as maiores freqüências relativas se referiram a trabalhos com dois autores, e nos periódicos os maiores percentuais foram de trabalhos com um autor.

A média geral de autores por artigo foi de 1,76 com uma dispersão de $25,8 \%$. 
Foi observado que as maiores médias de autores por artigo se encontraram nos anais de congressos, e que as mais baixas se referiram aos periódicos. Os resultados acima descritos fornecem indícios de padronização de publicação da área: nos periódicos, ênfase seria dada a trabalhos de autoria singular; nos anais de congressos, trabalhos apresentados em co-autoria, assertiva esta confirmada pelas maiores frequiências relativas de trabalhos com três autores nos congressos, se comparados com os periódicos pesquisados. Estes achados corroboram o trabalho de Urbizagastegui-Alvarado e Oliveira (2001), em que o autor assevera que, em publicações periódicas, os autores da área de ciências sociais teriam uma tendência de trabalhar e publicar isoladamente.

Esses primeiros resultados também são compatíveis com os trabalhos de Cardoso et al. (2005), cujos achados indicaram que $80,5 \%$ da produção de Contabilidade em periódicos de Administração é de um autor; de Vieira (2003), Leal et al. (2003), nos quais a maioria dos artigos na área de Marketing e Finanças, veiculados nas revistas de Administração, era de um autor, e o trabalho de Arkader (2003) que, em estudo das publicações na área de Operações, observou maior percentual de trabalhos de autoria singular nos periódicos, enquanto nos congressos havia maior percentual de artigos com dois ou mais autores. Observa-se que a área de Contabilidade poderia estar seguindo também os padrões de áreas correlatas, como Administração, observando-se a tendência de que a maioria dos trabalhos publicados em periódicos se refere a trabalhos de um autor.

Quanto ao gênero dos autores, verificou-se predominância de autores do sexo masculino na produção científica nos veículos estudados, com uma média geral de participação de 70,8\%, com uma dispersão de 6,4\%. Observou-se ainda que as maiores participações em todos os veículos de publicação foram de autores do sexo masculino. Tais achados confirmam os resultados do trabalho de Silva et al. (2005), que verificou maior participação masculina nas autorias em periódicos da área contábil. A tabela a seguir descreve o gênero dos autores por veículo de publicação:

\section{Tabela 4: Gênero dos Autores}

\begin{tabular}{|c|c|c|c|c|c|c|c|c|c|c|c|}
\hline \multirow{2}{*}{ Veículo / gênero } & \multicolumn{2}{|c|}{ EnAnpad } & \multicolumn{2}{|c|}{ Revista USP } & \multicolumn{2}{|c|}{ UnB Contábil } & \multicolumn{2}{|c|}{ Congresso USP } & \multirow{2}{*}{ Média } & \multirow{2}{*}{ DesvPad } & \multirow{2}{*}{ CV } \\
\hline & Quant. & $\%$ & Quant. & $\%$ & Quant. & $\%$ & Quant. & $\%$ & & & \\
\hline Feminino & 101 & $22,5 \%$ & 86 & $31,4 \%$ & 36 & $30,5 \%$ & 289 & $32,5 \%$ & $29,2 \%$ & $4,5 \%$ & $15,5 \%$ \\
\hline Masculino & 347 & $77,5 \%$ & 188 & $68,6 \%$ & 82 & $69,5 \%$ & 600 & $67,5 \%$ & $70,8 \%$ & $4,5 \%$ & $6,4 \%$ \\
\hline Total & 448 & $100,0 \%$ & 274 & $100,0 \%$ & 118 & $100,0 \%$ & 889 & $100,0 \%$ & & & \\
\hline
\end{tabular}

Com relação à filiação acadêmica dos autores, foi feita uma classificação por veículo de publicação e pelo vínculo declarado pelos autores, nos artigos dos periódicos e anais de congressos estudados, listando as dez instituições 
com as maiores frequiências relativas na participação da autoria. Analisando os resultados descritos na Tabela 5, verificaram-se indícios de forte endogenia de instituições nacionais, em especial nos dois periódicos analisados, tendo como universidades mais representativas na autoria e produção científica as suas próprias instituições sede: na Revista de Contabilidade e Finanças, que é publicada pela USP, observou-se que 74,5\% da produção são de autores vinculados à USP e no periódico UnB Contábil, 43,2\% das publicações são de autores com alguma vinculação com a UnB. Tal situação foi também verificada no Congresso USP de Controladoria e Contabilidade, onde 30,7\% são de autores da própria instituição. Apesar disto, observou-se no congresso EnAnpad, indícios de uma distribuição mais homogênea na autoria, se comparada aos demais veículos estudados; 34,4\% dos autores neste veículo está relacionada com instituições que participaram com um por cento ou menos do total da autoria, percentual este maior do que se comparado com os demais veículos de publicação investigados. A tabela a seguir ilustra as descrições mencionadas:

\section{Tabela 5: Filiação Acadêmica dos Autores (as 10 Mais Instituições por Veículo)}

\begin{tabular}{|c|c|c|c|c|c|c|c|}
\hline \multicolumn{2}{|c|}{ Enanpad } & \multicolumn{2}{|c|}{ Revista USP } & \multicolumn{2}{|c|}{ UnB Contábil } & \multicolumn{2}{|c|}{ Congresso USP } \\
\hline IES & $\%$ & IES & $\%$ & IES & $\%$ & IES & $\%$ \\
\hline USP & $17,2 \%$ & USP & $74,5 \%$ & UNB & $43,2 \%$ & USP & $30,7 \%$ \\
\hline UFRJ & $10,7 \%$ & UFSC & $3,3 \%$ & USP & $11,9 \%$ & UNB & $11,7 \%$ \\
\hline UNB & $6,7 \%$ & UFRJ & $1,8 \%$ & UFPE & $10,2 \%$ & UFPE & $6,7 \%$ \\
\hline FUCAPE & $6,1 \%$ & PUC/Camp & $1,5 \%$ & UFSC & $7,6 \%$ & FUCAPE & $6,2 \%$ \\
\hline UNISINOS & $4,8 \%$ & UNB & $1,5 \%$ & FAESA & $1,7 \%$ & UFSC & $3,5 \%$ \\
\hline PUC/SP & $4,6 \%$ & UBI/Portugal & $0,7 \%$ & UFPB & $2,5 \%$ & UFC & $3,1 \%$ \\
\hline UFSC & $4,6 \%$ & ESUDA & $0,7 \%$ & AEUDF & $1,7 \%$ & PUCSP & $2,8 \%$ \\
\hline UFPE & $4,4 \%$ & FUCAPE & $0,7 \%$ & UFRN & $1,7 \%$ & UFRJ & $2,7 \%$ \\
\hline UEM & $4,0 \%$ & ISCA/Portugal & $0,7 \%$ & UFRPE & $1,7 \%$ & FVC & $2,6 \%$ \\
\hline FVC & $2,5 \%$ & MAKENZIE & $0,7 \%$ & UNIMONTES & $1,7 \%$ & UFMG & $2,0 \%$ \\
\hline Outras & $34,4 \%$ & Outras & $13,9 \%$ & Outras & $16,1 \%$ & Outras & $27,9 \%$ \\
\hline
\end{tabular}

De maneira geral, os dados também revelaram indícios da existência de concentração de autoria vinculada a poucas instituições que apresentaram as mais altas frequiências relativas nos veículos de publicação estudados, em especial a USP, UnB, UFRJ, UFSC, UFPE, FUCAPE e UFSC. Os resultados acima descritos encontram simetria nos estudos de Chung et al. (1992), Zeff (1996), Willians e Rodgers (1996), Bino et al. (2002), Leal et al. (2003), Moriki e Martins (2003), Santana (2004), Cardoso et al. (2005), nos quais os autores também observaram indícios de endogenia em veículos de publicação, concentração de autores e instituições e monopólio de instituições na autoria e produção acadêmica de Contabilidade. 
Observa-se que esta concentração de autoria, verificada em poucas instituições nacionais, e a endogenia poderiam estar relacionadas ao baixo número de programas de pós-graduação stricto sensu na área de Contabilidade no Brasil, pois as instituições em que foram verificadas as mais altas frequiências relativas de autoria nos veículos analisados são as que mantêm programas de pós-graduação em Contabilidade. Conseqüientemente, tais instituições teriam professores, alunos e pesquisadores incentivados a publicar e apresentar trabalhos em periódicos e congressos com critérios de qualidade avaliados pela CAPES, o que também seria um dos requisitos para se avaliar e manter os conceitos dos referidos programas.

Como forma de complementar as análises anteriores, procurou-se identificar os autores mais prolíficos nos periódicos e anais de congressos em pauta, no período analisado, bem como a sua vinculação acadêmica. Observa-se que, em função dos aspectos éticos da pesquisa, optou-se por apresentar as iniciais dos nomes dos referidos autores, mantendo o anonimato, descrevendo e classificando os que publicaram e apresentaram, na soma total, acima de dez trabalhos, conforme tabela a seguir:

\section{Tabela 6: Autores Mais Prolíficos}

\begin{tabular}{|c|l|l|c|c|c|c|c|}
\hline & Autor & Vínculo IES & EnAnpad & R. USP & R. UnB & Cong. USP & Total \\
\hline $1^{\circ}$ & I.M.B & UFSC & 8 & 5 & 5 & 9 & 27 \\
\hline $2^{\circ}$ & R.G. & USP & 5 & 7 & & 8 & 20 \\
\hline $3^{\circ}$ & L.J.C. & USP & 5 & 4 & & 10 & 19 \\
\hline $4^{\circ}$ & L.C.M. & UFPE & 7 & & 2 & 8 & 17 \\
\hline $5^{\circ}$ & V.N. & FUCAPE & 7 & & & 8 & 15 \\
\hline $6^{\circ}$ & A.B.L. & USP & 7 & 5 & & 2 & 14 \\
\hline & A. dos S. & USP & 5 & 7 & & 2 & 14 \\
\hline $7^{\circ}$ & C.A.T.S. & UNB & 3 & 2 & 2 & 7 & 14 \\
\hline $8^{\circ}$ & A.J.C.T. & Fucape & 5 & & & 8 & 13 \\
\hline & M. de S.R. & USP & & 3 & & 10 & 13 \\
\hline $9^{\circ}$ & M.C.O. & UFC & 4 & 2 & & 5 & 11 \\
\hline & V.M.R.P. & UNIFOR & 4 & 4 & & 3 & 11 \\
\hline 10ㅇ․ & E.M. & USP & & 8 & & 2 & 10 \\
\hline & G. de A. M. & USP & & 2 & & 8 & 10 \\
\hline & R.F. & USP, PUCSP & 3 & & & 7 & 10 \\
\hline
\end{tabular}

$\mathrm{Na}$ análise dos autores mais prolíficos, nos veículos de publicação da área de Contabilidade, procurou-se classificar os sujeitos que apresentaram/publicaram dez artigos ou mais, conforme demonstrado na Tabela 6. Foram categorizados 15 autores que, juntos, corresponderam a $26,3 \%$ do total da produção acadêmica nos referidos anais de congressos e periódicos. Destes autores, mais da metade declararam vinculação acadêmica com a USP, corroborando os resultados anteriores sobre endogenia, concentração de autores e gerando indícios de haver 
uma elite de pesquisadores com vínculo declarado a esta instituição com os maiores percentuais de publicações nos periódicos e anais de congressos na área de Contabilidade.

Observa-se que essa baixíssima diversidade de origem dos autores poderia ser fator preocupante para a produção científica da área de Contabilidade, porque poderia estar apontando um ciclo vicioso que restringe a produção acadêmica da área aos estilos de autores e tendências de instituições a apresentarem trabalhos vinculados a linhas temáticas de seus interesses e que forçariam outras instituições a seguirem os seus padrões de publicação, engessando os padrões de publicação científica da área de Contabilidade no Brasil.

Contudo, como contributo ao não engessamento da produção científica na área de Contabilidade, alerta-se para a necessidade dos periódicos e congressos enfatizarem linhas editoriais e de apresentações que admitam e privilegiem a diversidade de abordagens metodológicas, minimizando-se, assim, este risco de padronização da produção científica na área.

Conforme fora estabelecido na abordagem metodológica deste trabalho, a segunda categoria de análise enfatizou o estudo da produtividade dos autores, mediante a lei bibliométrica de Lotka. Para esta análise, seguiram-se os modelos utilizados por Urbizagastegui-Alvarado (2002), Urbizagastegui-Alvarado e Oliveira (2001), Leal et al. (2003), Cardoso et al. (2005), Bino et al. (2002) e Chung et al. (1992).

Segundo Vanti (2002), a Lei de Lotka ou a Lei do Quadrado Inverso, objetiva medir a produtividade de autores, mediante um modelo de distribuição, tamanho e frequiência dos diversos autores em um conjunto de documentos. A expressão matemática que descreve a lei pode ser descrita como sendo o número de autores que publica $n$ artigos é:

$$
\alpha_{n}=\alpha_{1} \cdot \frac{1}{n^{2}}
$$

Onde $\alpha_{n}=$ número de autores que publicaram $\mathrm{n}$ artigos; $\alpha_{1}=$ número de autores que publicaram um artigo e $n=$ número total de artigos.

$\mathrm{Na}$ investigação empírica, optou-se por verificar o número de autores com intervalo de um a mais de sete artigos publicados nos veículos supracitados, conforme tabela a seguir: 


\section{Tabela 7: Percentual do Número de Artigos por Veículo de Publicação}

\begin{tabular}{|l|r|r|r|r|r|r|}
\hline \multicolumn{1}{|c|}{$\mathrm{n}^{\mathbf{o}}$ artigos / veículo } & $\begin{array}{r}\text { Anais do } \\
\text { EnAnpad }\end{array}$ & $\begin{array}{c}\text { Revista } \\
\text { USP }\end{array}$ & $\begin{array}{c}\text { UnB } \\
\text { Contábil }\end{array}$ & $\begin{array}{c}\text { Congresso } \\
\text { USP }\end{array}$ & $\begin{array}{c}\text { Total } \\
\text { da área }\end{array}$ & $\begin{array}{c}\text { Padrão } \\
\text { Lotka }\end{array}$ \\
\hline 1 Artigo & $72,3 \%$ & $70,3 \%$ & $84,8 \%$ & $71,0 \%$ & $72,5 \%$ & $60,8 \%$ \\
\hline 2 Artigos & $18,4 \%$ & $15,7 \%$ & $13,1 \%$ & $15,0 \%$ & $16,0 \%$ & $15,2 \%$ \\
\hline 3 Artigos & $4,2 \%$ & $6,4 \%$ & $1,0 \%$ & $7,0 \%$ & $5,6 \%$ & $6,8 \%$ \\
\hline 4 Artigos & $2,0 \%$ & $3,5 \%$ & $0,0 \%$ & $1,7 \%$ & $1,9 \%$ & $3,8 \%$ \\
\hline 5 Artigos & $1,7 \%$ & $2,3 \%$ & $1,0 \%$ & $2,6 \%$ & $2,1 \%$ & $2,4 \%$ \\
\hline 6 Artigos & $0,0 \%$ & $0,0 \%$ & $0,0 \%$ & $0,4 \%$ & $0,2 \%$ & $1,7 \%$ \\
\hline 7 Artigos & $1,1 \%$ & $1,2 \%$ & $0,0 \%$ & $0,7 \%$ & $0,9 \%$ & $1,2 \%$ \\
\hline Acima de 7 artigos & $0,3 \%$ & $0,6 \%$ & $0,0 \%$ & $1,7 \%$ & $0,9 \%$ & $8,1 \%$ \\
\hline Total & $\mathbf{1 0 0 , 0 \%}$ & $\mathbf{1 0 0 , 0 \%}$ & $\mathbf{1 0 0 , 0 \%}$ & $\mathbf{1 0 0 , 0 \%}$ & $\mathbf{1 0 0 , 0 \%}$ & $\mathbf{1 0 0 , 0 \%}$ \\
\hline
\end{tabular}

Segundo Chung et al. (1992), para a Lei de Lotka, o número de autores com um único trabalho publicado deveria ser $60,8 \%$ do total dos autores. A partir daí, usa-se a regra do Quadrado Inverso para calcular os percentuais de autores com $\mathrm{n}$ artigos publicados. Partiu-se desta lógica para calcular os valores percentuais que seriam comparados com os dados observados dos anais de congressos e dos periódicos analisados neste estudo.

Verificou-se uma tendência de padronização na quantidade de artigos por autor nos veículos de publicação da área Contábil, pois as maiores frequêencias relativas se referiram a um artigo apresentado/publicado por autor. A média total da área para um artigo foi de 72,5\% da produção acadêmica, seguida por dois artigos, com uma média geral de $16 \%$. Os resultados dão indícios de que a área de Contabilidade também poderia estar seguindo padrões das áreas correlatas, tais como Administração, pois os dados empíricos corroboram os estudos de Bertero, Binder e Vasconcelos (2003), Vieira (2003), Leal et al. (2003), Arkader (2003), nos quais os autores observaram que os maiores percentuais da produção científica nas áreas de estratégia, marketing, finanças e operações se referiam à produção de autoria única.

Visando ter indicadores mais consistentes sobre os padrões de publicação na área de Contabilidade, os dados empíricos acima descritos foram utilizados nos testes estatísticos de aderência, para verificar se eram compatíveis com os padrões da Lei bibliométrica de Lotka e no cálculo do coeficiente C da referida lei. Segundo Chung et al. (2002), Cardoso et al. (2005) e Leal et al. (2003), o coeficiente C é estimado segundo a amostra e o padrão da lei de Lotka é dois. Valores acima deste coeficiente indicam que autores com uma publicação são maiores, em termos percentuais, do que o padrão da Lei de Lotka. Neste estudo, optou-se por calcular o coeficiente $\mathrm{C}$ de cada veículo de publicação da área de Contabilidade, além de comparar a distribuição empírica com os padrões da Lei de Lotka, conforme a fórmula: 


$$
\operatorname{Ln}\left(\frac{\alpha_{n}}{\alpha_{1}}\right)=-C \cdot \operatorname{Ln}(n)
$$

Verificou-se que uma das críticas do trabalho de Urbizagastegui-Alvarado (2002) aos estudos bibliométricos, realizados no Brasil, foi que alguns não utilizaram teste estatístico para avaliar o ajustamento dos dados empíricos de produtividade dos autores das diversas áreas com o padrão da Lei de Lotka. Visando minimizar esta deficiência, e seguindo orientação do autor supracitado, optou-se em utilizar o teste Kolmogorov-Smirnov [K-S] para duas amostras não relacionadas para avaliar o ajuste da distribuição teórica da Lei de Lotka com a distribuição observada de cada um dos veículos analisados. Segundo Siegel (1975), o teste K-S é uma prova de aderência, uma vez que se refere ao grau de concordância entre a distribuição de um conjunto de dados amostrais (observados) e uma distribuição teórica específica. Desta forma, foram estabelecidas as seguintes hipóteses para o teste.

$H_{0}$ : Não existe diferença significativa entre a distribuição observada e a Lei de Lotka.

$H_{l}$ : Existe diferença significativa entre a distribuição observada e a Lei de Lotka.

Para se efetuar o teste, trabalhou-se com um nível de significância de 0,05, através do programa estatístico SPSS 10.0 (Statistical Package Social Science). Os resultados do cálculo do coeficiente $\mathrm{C}$ bem como do teste estatístico são apresentados na tabela a seguir:

\section{Tabela 8: Cálculo de C e Resultados dos Testes Estatísticos}

\begin{tabular}{|l|c|c|c|l|}
\hline Veículo de publicação & C & P Value & Alfa & \multicolumn{1}{c|}{ Decisão } \\
\hline Anais do EnAnpad (CCG) & 1,97 & 0,627 & 0,05 & Aceita Ho - são iguais \\
\hline Revista Contabilidade e Finanças & 2,16 & 0,964 & 0,05 & Aceita Ho - são iguais \\
\hline Revista UnB Contábil & 2,53 & 0,022 & 0,05 & Rejeita Ho - diferentes \\
\hline Anais do Congresso USP Controladoria & 2,12 & 0,627 & 0,05 & Aceita Ho - são iguais \\
\hline Total da área de Contabilidade & $\mathbf{2 , 1 3}$ & $\mathbf{0 , 6 2 7}$ & $\mathbf{0 , 0 5}$ & Aceita Ho - são iguais \\
\hline
\end{tabular}

Os testes sugeriram que as distribuições de freqüência dos periódicos e anais de Contabilidade se ajustam à distribuição da Lei de Lotka, evidenciados no teste estatístico Kolmogorov-Smirnov [K-S], excetuando-se o periódico UnB Contábil. Uma possível explicação da não aderência do periódico UnB Contábil à Lei de Lotka no contexto dos demais periódicos e congressos analisados poderia ser a ênfase na autoria única, que representou $84,8 \%$ do total da produção neste veículo, enquanto os outros se situaram na faixa de $70 \%$. No cálculo do coeficiente C, verificou-se nos veículos em que o teste estatístico sugeriu não haver diferença 
significativa, valores aproximados ao padrão da Lei de Lotka, oscilando de 1,97 a 2,16 . Neste caso também a exceção foi a revista UnB Contábil, que apresentou o coeficiente $\mathrm{C}$ mais elevado $(2,53)$. Verificando-se o total da área de Contabilidade e baseando-se no cálculo do coeficiente $\mathrm{C}$, pode-se sugerir que o número de autores com mais de uma publicação na amostra de veículos de publicação de Contabilidade investigada poderia ser estimado pela seguinte equação:

$$
\alpha_{n}=\alpha_{1} \cdot \frac{1}{n^{2,13}}
$$

Onde: $\alpha_{n}=$ número de autores que publicaram $\mathrm{n}$ artigos; $\alpha_{1}=$ número de autores que publicaram um artigo, que neste caso é $0,725(72,5 \%)$ e n $=$ número total de artigos.

Apesar de que os dados empíricos de autoria em Contabilidade apresentam um coeficiente $\mathrm{C}$ maior do que os padrões teóricos de Lotka $(2,13>2,00)$, os testes estatísticos sugeriram não haver diferença significativa entre eles, evidenciando que aderem à referida distribuição teórica.

Como forma de complementar as análises, optou-se por fazer uma comparação com outros estudos da Lei de Lotka, em diversas áreas de conhecimento no Brasil. Urbizagastegui-Alvarado (2002) usou dados reportados em artigos publicados em revistas brasileiras e anais de congressos nacionais, replicando a aplicação da lei bibliométrica de Lotka à literatura brasileira em dez campos diferentes, utilizando-se o poder inverso, pelos métodos do mínimo quadrado e probabilidade máxima, além de calcular o coeficiente C. O referido autor concluiu que das dez literaturas verificadas, somente as literaturas de medicina, siderurgia, jaca e biblioteconomia se ajustaram ao modelo teórico da Lei de Lotka. Contudo o autor observou que utilizou o modelo do poder inverso generalizado pelo método dos mínimos quadrados conjuntamente com a análise do teste Kolmogorov-Smirnov (K-S). Urbizagastegui-Alvarado e Oliveira (2001), em estudo sobre a produtividade de autores em Antropologia, sugeriram que os dados empíricos não se ajustaram aos padrões de Lotka, utilizando-se o teste do qui-quadrado, apresentando um coeficiente $C$ abaixo dos padrões $(0,449<2,00)$. Em Contabilidade nos EUA, o estudo de Chung et al. (1992) sugeriu que os dados empíricos se ajustavam ao padrão Lotka; apesar de apresentarem um coeficiente C abaixo do padrão $(1,872<2,00)$, não informaram qual teste estatístico foi utilizado. Em finanças, Leal et al. (2003) sugeriram a não aderência ao padrão; utilizando o teste do qui-quadrado, encontraram um coeficiente $\mathrm{C}$ maior do que o padrão (2,44 > 2,00). Cardoso et al. (2005), estudando artigos de Contabilidade publicados em periódicos de Administração e Economia, sugeriram a não aderência aos padrões de Lotka, não informando o teste de ajuste utilizado, evidenciando um 
coeficiente $\mathrm{C}$ acima dos padrões $(2,54$ > 2,00). Os estudos acima descritos são evidenciados na tabela a seguir.

\section{Tabela 9: Resultados Comparativos de Estudos Bibliométricos em Outras Áreas}

\begin{tabular}{|c|c|c|c|c|}
\hline Área do Conhecimento & C & Ajuste & Teste & Autores \\
\hline Direito & 1,86 & Não & K-S & $\begin{array}{l}\text { Braga et al. (1975 como citado em Urbizagastegui- } \\
\text { Alvarado, 2002). }\end{array}$ \\
\hline Medicina & 2,76 & Sim & K-S & $\begin{array}{l}\text { Oliveira e Caldeira (1976 como citado em } \\
\text { Urbizagastegui-Alvarado, 2002). }\end{array}$ \\
\hline Microbiologia & 2,63 & Não & K-S & $\begin{array}{l}\text { Sá (1976 como citado em Urbizagastegui-Alvarado, } \\
\text { 2002). }\end{array}$ \\
\hline Arquivo G. Vargas & 0,881 & Não & K-S & $\begin{array}{l}\text { Bomeny (1978 como citado em Urbizagastegui- } \\
\text { Alvarado, 2002). }\end{array}$ \\
\hline Siderurgia & 2,18 & Sim & K-S & $\begin{array}{l}\text { Gusmão (1978 como citado em Urbizagastegui- } \\
\text { Alvarado, 2002). }\end{array}$ \\
\hline Veterinária & 0,621 & Não & K-S & $\begin{array}{l}\text { Caldeira (1979 como citado em Urbizagastegui- } \\
\text { Alvarado, 2002). }\end{array}$ \\
\hline Biblioteconomia & 2,51 & Sim & K-S & $\begin{array}{l}\text { Foresti e Martins (1978 como citado em } \\
\text { Urbizagastegui-Alvarado, 2002). }\end{array}$ \\
\hline Universidade & 1,44 & Não & K-S & $\begin{array}{llll}\text { Targino e Caldeira (1988 como citado em } \\
\text { Urbizagastegui-Alvarado, 2002). }\end{array}$ \\
\hline Marketing & 1,25 & Não & K-S & $\begin{array}{l}\text { Amaral (1996 como citado em Urbizagastegui- } \\
\text { Alvarado, 2002). }\end{array}$ \\
\hline Literatura & 2,14 & Sim & K-S & $\begin{array}{l}\text { Oliveira (1983 como citado em Urbizagastegui- } \\
\text { Alvarado, 2002). }\end{array}$ \\
\hline Antropologia & 0,449 & Não & $\chi^{2}$ & Urbizagastegui-Alvarado e Oliveira (2001) \\
\hline Contabilidade EUA & 1,872 & Sim & N. I & Chung et al. (1992) \\
\hline Finanças & 2,44 & Não & $\chi^{2}$ & Leal et al. (2003) \\
\hline Contabilidade & 2,54 & Não & N. I. & Cardoso et al. (2005) \\
\hline
\end{tabular}

Conforme se observa na Tabela 9, dos 14 estudos listados das diversas áreas, apenas cinco evidenciaram ajuste aos padrões bibliométricos de Lotka. Nas demais áreas, os estudos sugeriram o não ajustamento, confirmado pelos testes estatísticos realizados em cada um dos trabalhos acima descritos.

Comparando-se com estudos na área correlata, os anais de congressos e periódicos de Contabilidade pesquisados apresentaram características diferentes dos estudos de Cardoso et al. (2005) na área de Contabilidade, e Leal et al. (2003) em Finanças no Brasil. Como os estudos dos referidos autores foram feitos em periódicos de Administração e Economia, pode-se sugerir que há diferenças entre a produtividade de autores em periódicos e anais de congressos específicos de Contabilidade, e publicações de autores de artigos de Contabilidade em periódicos de áreas afins.

Assim, os dados empíricos sugeriram que o total dos autores dos anais de congressos e periódicos pesquisados, na área de Contabilidade, poderia ter uma produtividade estatisticamente igual aos padrões descritos pela Lei de Lotka. 


\section{Conclusão e Sugestões}

O objetivo do estudo foi analisar, sob o ponto de vista da teoria bibliométrica, a produtividade científica dos autores em anais de congressos e periódicos na área de Contabilidade brasileira. Respondendo aos objetivos da pesquisa, observou-se que na área de Contabilidade houve uma média geral de 1,76 autores por artigo, variando em função do tipo de veículo de publicação: nos periódicos verificou-se média menor e, nos anais de congressos, este indicador tenderia a aumentar. Concluiu-se que a maioria da produção acadêmica nos periódicos da área de Contabilidade se referiu a trabalhos de um autor, dando indícios de que os pesquisadores tendem a publicar de forma isolada, sugerindo um quadro de falta de grupos de pesquisa com publicações periódicas. Ainda neste sentido, observou-se indícios de padronização de publicação da área, nos periódicos dando-se ênfase a trabalhos de autoria singular e, nos anais de congressos, a trabalhos apresentados em co-autoria, variando de dois a três autores. Verificouse ainda predominância de autores do sexo masculino na publicação da área, correspondendo a mais de $70 \%$ da média geral de trabalhos publicados e apresentados nos veículos pesquisados.

Com relação ao vínculo institucional dos autores, os indícios apontam forte endogenia de instituições nacionais, em especial dos dois periódicos analisados, tendo como universidades mais representativas, na autoria e produção científica, as suas próprias instituições sedes (USP e UnB), sugerindo que as instituições supracitadas acreditam ter conhecimento científico relevante para publicação somente o que vem de si, enfatizando publicações de autores que têm algum vínculo com as referidas instituições. Contudo os resultados dos anais do EnAnpad sugeriram distribuição mais homogênea na vinculação acadêmica dos autores na área. Ainda nesta categoria, os resultados sugeriram a existência de concentração de autoria vinculada a poucas instituições, que apresentaram as mais altas frequiências relativas nos veículos de publicação estudados, em especial a USP, UnB, UFRJ, UFSC, UFPE e FUCAPE, denotando indícios de uma elite de pesquisadores e instituições detentoras dos maiores percentuais de publicação na área de Contabilidade. Tais resultados podem também ser confirmados pela categorização dos autores mais prolíficos da área, composta por quinze sujeitos que, juntos, foram responsáveis por mais de $26 \%$ da produção científica na área e que mantêm vínculo com as instituições consideradas elitizadas.

Com relação à produtividade dos autores nos veículos analisados, concluiu-se que a maioria da produção acadêmica se referiu a autores que publicaram/ apresentaram apenas um artigo, tendo a média total da área de 72,5\% da produção acadêmica, o que denotou indícios de falta de continuidade nas pesquisas, 
corroborando as sugestões anteriores de falta de grupos de pesquisas com publicações periódicas e pesquisas longitudinais na área.

Concluiu-se ainda que a produtividade média de autores, nos veículos supracitados, pode ser estimada por equação que apresentou, para todos os dados, coeficiente $\mathrm{C}$ de 2,13. Apesar de apresentar coeficiente acima dos padrões preconizados pela Lei Bibliométrica de Lotka, os testes estatísticos sugeriram adequação dos dados empíricos à referida lei, com significância de 0,05; excetuase o periódico UnB Contábil; sugere-se que os padrões de produtividade dos veículos de publicação contábeis pesquisados são estatisticamente iguais aos padrões da referida lei.

Considerando as limitações da pesquisa, por utilizar como amostra os veículos de publicação, na área de Contabilidade, classificados pelo Qualis/Capes, alertase que tais informações não podem ser generalizadas para outros periódicos e veículos de publicação nem para outras áreas, tampouco foi objetivo deste trabalho, que tentou entender e explicar os padrões de produtividade dos autores nestes veículos de publicação pesquisados. Contudo se observa que os achados da pesquisa podem contribuir sobremaneira para o entendimento da produção científica da área de Contabilidade.

Como sugestões para futuras pesquisas, recomenda-se que sejam feitos estudos que englobam todos os periódicos e anais de congresso na área de Contabilidade; relacionar a qualidade dos periódicos e anais de congressos com os padrões bibliométricos e avaliar as referências bibliográficas dos referidos veículos de publicação; avaliar a produtividade dos autores, utilizando outros indicadores bibliométricos; comparar a produtividade de autores com diferentes interesses científicos; comparar a produtividade de autores em áreas correlatas, como Administração, Economia, Direito e Ciências Sociais, criando-se uma perspectiva de fronteira com outras áreas.

\section{Artigo recebido em 04.03.2006. Aprovado em 05.03.2007.}

\section{RefERÊNCIAS BibliográficAs}

Alvarenga, L. (2000).

Contribuições para os estudos sobre a pesquisa educacional no Brasil: análise bibliométrica de artigos da Revista Brasileira de Estudos
Pedagógicos 1944-1974. Revista Brasileira de Estudos Pedagógicos, 81(198), 244-272. 
Arkader, R. A. (2003).

A pesquisa científica em gerência de operações no Brasil. Revista de Administração de Empresas, 43(1), 70-79.

Bertero, C. O.,

Binder, M. P., \&

Vasconcelos, F. C. (2003).

Estratégia empresarial: a produção científica brasileira entre 1991 e 2002. Revista de Administração de Empresas, 43(4), 48-62.

Bertero, C. O.,

Caldas, M. P., \&

Wood, T., Jr. (2005).

Produção científica em administração no Brasil: o estado da arte. São Paulo: Atlas.

Bino, P. G. D.,

Subash, S., \&

Ramanathan, A. (2002).

Concentration in knowledge output: a case of economics journals. The European Journal of Comparative Economics, 2(2), 261-279.

Campos, M. (2003).

Conceitos atuais em bibliometria. Arquivos Brasileiros Oftalmologia, 66(1), 1-22.

Cardoso, R. L.,

Mendonça O. R.,

Neto, Riccio, E. L., \&

Sakata, M. C. G. (2005).

Pesquisa científica em contabilidade entre 1990 e 2003. Revista de Administração de Empresas, 45(2), 43-55.
Cardoso, R. L.,

Pereira, C. A., \&

Guerreiro, R. (2004, setembro).

A produção acadêmica em custos no âmbito do EnAnpad: uma análise de 1998 a 2003. Anais do Encontro Nacional da Associação Nacional de Pós-Graduação e Pesquisa em Administração, Curitiba, PR, Brasil, 28.

Chung, K. H.,

Pak, H. S., \&

Cox, R.A. K. (1992)

Patterns of research output in the accounting literature: a study of the bibliometric distribuitions. Abacus, 28(2), 168-180.

Fogarty, T. J. (2004).

Sustained research productivity in accouting: a study of the senior cohort. Global Perspectives in Accounting Education, 1(1), 31-58.

Frezatti, F., \&

Borba, J. A. (2000).

Análise dos traços de tendência de uma amostra das revistas científicas na área de contabilidade publicadas na língua inglesa. Caderno de Estudos / Fundação Instituto de Pesquisas Contábeis, Atuariais e Financeiras, 3(24), 50-78.

Gil,A.C. (1996).

Como elaborar projetos de pesquisa. São Paulo: Atlas.

Leal, R.,

Oliveira, J., \&

Soluri, A. (2003).

Perfil da pesquisa em finanças no Brasil. Revista de Administração de Empresas, 43(1), 91-104. 
Leite, G. A., Filho (2004).

$A$ relação orientador-orientando $e$ suas influências no processo de elaboração de dissertações e teses dos programas de pós-graduação em contabilidade da cidade de São Paulo. Dissertação de mestrado. Universidade de São Paulo, São Paulo, SP, Brasil.

Martins, G. A. de, \&

Silva, R. B. C. da (2005, julho).

Plataforma teórica - trabalhos do $3^{\circ} \mathrm{e}$ $4^{\circ}$ congressos USP de controladoria e contabilidade: um estudo bibliométrico. Anais do Congresso USP de Controladoria e Contabilidade, São Paulo, SP, Brasil, 5.

Mattar, F. N. (1996).

Pesquisa de marketing (Edição Compacta). São Paulo: Atlas.

Moriki, A. M. N., \&

Martins, G. A. (2003, julho).

Análise do referencial bibliográfico de teses e dissertações sobre contabilidade e controladoria. Anais do Congresso USP de Controladoria e Contabilidade, São Paulo, SP, Brasil, 3.

Oliveira, M. C. (2001).

Análise do conteúdo e forma dos periódicos nacionais de Contabilidade. Tese de doutorado. Universidade de São Paulo, São Paulo, SP, Brasil.

Riccio, E. L.,

Carastan, J. T., \&

Sakata, M. (1999).

Accounting research in brazilian universities: 1962 - 1999. Caderno de Estudos / Fundação Instituto de Pesquisas Contábeis, Atuariais e Financeiras, 11(22), 35-44.
Santana, C. M. (2004).

Produção do conhecimento em contabilidade social no Brasil (1990 a 2003) uma abordagem bibliométrica. Dissertação de mestrado. Universidade de São Paulo, São Paulo, SP, Brasil.

Siegel, S. (1975).

Estatística não-paramétrica para as ciências do comportamento. São Paulo: McGraw-Hill.

Silva, A. C. B.,

Oliveira, E. C. de, \&

Ribeiro, J. F., Filho (2005).

Revista contabilidade e finanças USP: uma comparação entre os períodos 1989/2001 e 2001/2004. Revista Contabilidade e Finanças, 39, 20-32.

Souza, F. C. de, \&

Rasche, F. (1999).

Produção de literatura profissional em educação em informação documentária no estado de Santa Catarina (Relatório PROBIC No 43). Florianópolis, SC, Universidade Federal de Santa Catarina.

Theóphilo, C. R., \&

Iudícibus, S. de (2005, setembro).

Uma análise crítico-epistemológica da produção científica em contabilidade no Brasil. Anais do Encontro Nacional da Associação Nacional de Pós-Graduação e Pesquisa em Administração, Brasília, DF, Brasil, 29.

Urbizagastegui-Alvarado, R. (2002).

A lei de Lotka na bibliometria brasileira. Ciência da Informação, 31(2), 14-20. 
Urbizagastegui-Alvarado, R., \&

Oliveira, M. de (2001).

A produtividade dos autores na antropologia brasileira. DataGramaZero. Revista de Ciência da Informação, 2(6), 8-19.

Vanti, N. (2002).

Da bibliometria à webometria: uma exploração conceitual dos mecanismos utilizados para medir o registro da informação e a difusão do conhecimento. Ciência da Informação, 31(2), 152-162.

Vieira, F. G. (2003).

Narciso sem espelho: a publicação brasileira de marketing. Revista de
Administração de Empresas, 43(1), 81-90.

Volpato, G. L. (2002).

Publicação científica. Botucatu: Santana.

Willians, P. F., \&

Rodgers, J. L. (1996).

Patterns of research productivity and knowledge creation at the accounting review: 1967-1993. The Accounting Historians Journal, 23(1), 445-470.

Zeff, S. A. (1996).

A study of academic research journals in accounting. Accounting Horizons, 10(3), 158-177. 